\title{
Human factors analysis and classification system for the oil and gas industry (HFACS-OGI)
}

Theophilus, S, Esenowo, V, Arewa, A, Ifelebuegu, A, Nnadi, EO \& Mbanaso, $F$

Author post-print (accepted)

Original citation \& hyperlink:

Theophilus, S, Esenowo, V, Arewa, A, Ifelebuegu, A, Nnadi, EO \& Mbanaso, F 2017, 'Human factors analysis and classification system for the oil and gas industry (HFACSOGI)' Reliability Engineering \& System Safety, vol 167, pp. 168-176

https://dx.doi.org/10.1016/j.ress.2017.05.036

DOI $\quad 10.1016 /$ j.ress.2017.05.036

ISSN 0951-8320

Publisher: Elsevier

NOTICE: this is the author's version of a work that was accepted for publication in Reliability Engineering \& System Safety. Changes resulting from the publishing process, such as peer review, editing, corrections, structural formatting, and other quality control mechanisms may not be reflected in this document. Changes may have been made to this work since it was submitted for publication. A definitive version was subsequently published in Reliability Engineering \& System Safety, [167, (2017)] DOI: 10.1016/j.ress.2017.05.036

C 2017, Elsevier. Licensed under the Creative Commons Attribution-

NonCommercial-NoDerivatives $\mathbf{4 . 0}$ International

http://creativecommons.org/licenses/by-nc-nd/4.0/

Copyright $\subseteq$ and Moral Rights are retained by the author(s) and/ or other copyright owners. A copy can be downloaded for personal non-commercial research or study, without prior permission or charge. This item cannot be reproduced or quoted extensively from without first obtaining permission in writing from the copyright holder(s). The content must not be changed in any way or sold commercially in any format or medium without the formal permission of the copyright holders.

This document is the author's post-print version, incorporating any revisions agreed during the peer-review process. Some differences between the published version and this version may remain and you are advised to consult the published version if you wish to cite from it. 


\title{
Human factors analysis and classification system for the oil and gas industry (HFACS-OGI)
}

\begin{abstract}
The oil and gas industry has been beset with several catastrophic accidents, most of which have been attributed to organisational and operational human factor errors. The current HFACS developed for the aviation industry, cannot be used to simultaneously analyse regulatory deficiencies and emerging violation issues, such as sabotage in the oil and gas industry. This paper presents an attempt to improve the existing HFACS investigation tool and proposes a novel HFACS named the Human Factors Analysis and Classification System for the Oil and Gas Industry (HFACS-OGI). Results found the HFACS-OGI system to be suitable for categorising accidents, following the analysis of 11 accident reports from the US Chemical Safety Board (US CSB). The HFACS-OGI system moreover revealed some significant relationships between the different categories. Furthermore, the results indicated that failures in national and international industry regulatory standards would automatically create the preconditions for accidents to occur.
\end{abstract}

\section{Keywords}

Human and Organisational Factor; Accident Causation; Accident Analysis; Human Factors Analysis and Classification System; Oil and Gas Industry

\section{Introduction}

The process industry has experienced some devastating accidents and statistics have shown that these are mostly attributed to human factors [1,2]. For example the Bhopal toxic release (1984), one of the worst industry disasters, resulted in 2500-6000 fatalities and over 200,000 in- juries [3] . The Flixborough explosion (1974) caused 28 fatalities and the near total annihilation of the NYPRO plant [4] . The BP Texas City refinery explosion (2005) resulted in around 15 fatalities [5] and the Piper Alpha offshore oil industry disaster (1988) left 167 dead and dozens badly injured [6]. These have all been investigated and found to be a result of both direct and indirect human factor failings. Studies have shown that some of the investigative tools and measures adopted were not robust enough to avoid accidents, especially in an industry prone to risks and accidents. Shappell and Wiegmann therefore assert that it is imperative to take accident investigation beyond the actions of immediate personnel [7]. An attempt to accomplish this resulted in the development of the Human Factors Analysis and Classification System (HFACS) by Shappell and Wiegmann, for use in the investigation of US military aviation accidents [8-11]. The framework was based on James Reason's "Swiss Cheese" model which explained the occurrence of system failure at four levels: 1) Organisational failures, 2) Unsafe supervision, 3) Pre- conditions for unsafe acts and 4) Unsafe acts. The framework uses a systems approach to identify deficiencies that have led to an 
accident rather than focusing on and blaming the individuals involved [11, 12]. Whilst the HFACS framework was originally developed and applied successfully in the analysis of aviation accidents [11], other industries have also successfully used the original framework, or a modified version, in accidents analysis. These include the maritime and railway industries and medical organisations [13-18]. Table 1 shows that the HFACS framework as it was originally constituted has been modified for use in several different sectors.

The existing HFACS is effective for the analysis of human factors, particularly as it relates to safety culture, management commitment, safety leadership [25] , organisational erosive drift [26] , technical failure of ageing equipment and the operators' lack of knowledge or competency [26,27] . It cannot however simultaneously analyses regulatory deficiencies [28, 29] and emerging violation issues like sabotage, in response to problematic organisational factors particular to the oil and gas industry [17]. At present, there is no Human Factors Analysis and Classification System (HFACS) specifically designed for the oil and gas industry. A HFACS framework specifically for accident analysis in the oil and gas industry therefore would be particularly advantageous.

Table 1: List of HFACS Modifications for the Development of HFACS-OGI

\begin{tabular}{|c|c|c|c|c|}
\hline Studies & Author(S) & Sector & $\begin{array}{l}\text { HFACS } \\
\text { Version }\end{array}$ & Key Modifications \\
\hline $\begin{array}{l}\text { A human and organisational } \\
\text { factors (HOFs) analysis } \\
\text { method for marine casualties } \\
\text { using HFACS-Maritime } \\
\text { Accidents (HFACS-MA) }\end{array}$ & {$[15]$} & Marine & HFACS-MA & $\begin{array}{l}\text { The fifth level added with } \\
\text { legislation gaps, } \\
\text { administration oversight and } \\
\text { design gaps as categories. }\end{array}$ \\
\hline $\begin{array}{l}\text { Use of HFACS-FCM in fire } \\
\text { prevention modeling on board } \\
\text { ships }\end{array}$ & {$[18]$} & Shipping & HFACS-FCM & \\
\hline $\begin{array}{l}\text { Operator error and system } \\
\text { deficiencies: Analysis of } 508 \\
\text { mining incidents and accidents } \\
\text { from Queensland, Australia } \\
\text { using HFACS }\end{array}$ & {$[19]$} & Mining & HFACS-MI & $\begin{array}{l}\text { The addition of the fifth } \\
\text { level called outside factors } \\
\text { with regulatory factors and } \\
\text { others as categories. }\end{array}$ \\
\hline $\begin{array}{l}\text { Application of a human error } \\
\text { framework to conduct train } \\
\text { accident/incidents } \\
\text { investigations }\end{array}$ & {$[17]$} & Railroad & HFACS-RR & $\begin{array}{l}\text { The addition of the fifth } \\
\text { level called outside factors } \\
\text { with two categories called } \\
\text { regulatory oversight and } \\
\text { economic/political/social/leg } \\
\text { al environment. The addition }\end{array}$ \\
\hline
\end{tabular}




\begin{tabular}{|c|c|c|c|c|}
\hline & & & & $\begin{array}{l}\text { of acts of sabotage in } \\
\text { operator acts level. }\end{array}$ \\
\hline The Human Factors Analysis & \multirow[t]{5}{*}[12]{} & \multirow[t]{5}{*}{ Healthcare } & Modified- & Substituting some categories \\
\hline Classification System & & & HFACS & at preconditions for unsafe \\
\hline (HFACS) Applied to Health & & & & acts level with the fitness of \\
\hline \multirow[t]{2}{*}{ Care } & & & & duty, chronic performance \\
\hline & & & & limitation. \\
\hline \multirow{8}{*}{$\begin{array}{l}\text { Developing the understanding } \\
\text { of underlying causes of } \\
\text { construction fatal accidents }\end{array}$} & \multirow[t]{8}{*}[20]{} & \multirow[t]{8}{*}{ Construction } & Modified- & The addition of a fifth level \\
\hline & & & HFACS & called external influences \\
\hline & & & & with the following \\
\hline & & & & categories: political \\
\hline & & & & influences, regulatory \\
\hline & & & & influences, market \\
\hline & & & & influences, and social \\
\hline & & & & influences. \\
\hline Evaluation of the Human & \multirow[t]{8}{*}[21]{} & \multirow[t]{8}{*}{ Aviation } & Modified - & The addition of a fifth level \\
\hline Factors Analysis and & & & HFACS & called outside influence with \\
\hline Classification System as a & & & & the following categories: \\
\hline \multirow[t]{5}{*}{ Predictive Model } & & & & maintenance issues, \\
\hline & & & & airport/airport personnel, \\
\hline & & & & regulatory impact, air traffic \\
\hline & & & & issues and other person \\
\hline & & & & involvement. \\
\hline Evaluation of the HFACS- & \multirow[t]{4}{*}[22]{} & \multirow[t]{4}{*}{ Aviation } & \multirow[t]{4}{*}{ HFACS-ADF } & The addition of a category \\
\hline ADF safety classification & & & & called defences. \\
\hline \multicolumn{2}{|l|}{ system: Inter-coder consensus } & & & \\
\hline \multicolumn{2}{|l|}{ and intra-coder consistency } & & & \\
\hline Helicopter maintenance error & {$[23]$} & Aviation & HFACS-ME & The modification includes \\
\hline analysis: Beyond the third & & & & the addition of maintainer \\
\hline order of the HFACS-ME & & & & conditions. \\
\hline Helicopter maintenance error & {$[24]$} & Aviation & HFACS-ME & The modification includes \\
\hline analysis: Beyond the & & & & the addition of \\
\hline third order of the HFACS-ME & & & & maintainer conditions \\
\hline
\end{tabular}

\subsection{Analysis of proposed framework for the oil and gas industry (HFACS-OGI)}

Original HFACS was based on Reasons theory of accident causation. However, HFACs has been modified to fit specific industries and applications. The proposed HFACS-OGI took into consideration oil and gas technical reports like the 2014 SPE technical report 'The Human Factor: Process Safety and Culture' produced after a two-day summit held in July 2012 on human factors as it affects the oil and gas industry and the best way forward[7]. Proposed changes focused on preventing catastrophic accident, particularly toxic 
releases, fire and explosion associated with Control of major accident hazards (COMAH) regulations (1999)[29].

\subsection{Unsafe Acts (Level 1)}

The Health and Safety Executive defines an unsafe act as: "any act that deviates from a generally recognized safe way or specified method of doing a job and increases the potential of an accident" [30]. Unsafe acts as shown in the proposed HFACS-OGI ( Fig. 2 ) could be as a result of error by omission (where a required action was disregarded) or error by commission (where an incorrect action was performed) [31] . In both cases, these errors are unintentional and unplanned. In the case of violation however, the error is intentional although usually the perpetrators perceived they had a better idea, a quicker process, superior knowledge or a different way to accomplish a given task. Sometimes violations occur due to the impression that there are too many layers of protection which are bypassed with no intention to cause deliberate harm.

\subsubsection{Act of Sabotage}

An act of sabotage suggests intentionality. It may be defined as a deliberate act to negatively affect the system, process, work or produc- tion in a plant, system, factory or workplace that may lead to a serious accident or damage, in response to a challenging identified organisa- tional factor [17] . In this form of violation, all layers of protection are deliberately removed to cause harm.

There are two main theories that have been advanced to explain how water entered Tank 610 in the Bhopal disaster: 1) water-washing of the pipes and 2) sabotage [32] . The second theory states that an act of sabotage by an aggrieved employee in response to organisational is- sues caused one of the world's worst process safety accidents. Kalelkar and Little [33] argued in support of the second theory that although "minor incidents of process sabotage by employees had occurred pre- viously at the Bhopal plant, and, indeed, occur from time to time in industrial plants all over the world...it was during a shift change that a disgruntled operator entered the storage area and hooked up one of the readily available rubber water hoses to Tank 610, with the inten- tion of contaminating and spoiling the tank's contents. "[33] . Opera- tors' acts of sabotage can take different forms: working slowly, destroy- ing equipment and polluting the system among others. Such interven- tions in normal operational procedures might result in severe conse- quences like fire, major explosions, toxic releases and environmental contamination [34] .

Although it was only after the 9/11 terrorist attacks in New York City that the chemical industries included sabotage in their formal risk as- sessments [34], it is essential to differentiate between acts of sabotage and terrorist attacks. An act of sabotage is an internal act carried out by a disgruntled employee in response to a challenging organisational issue. A terrorist act on the other hand is mostly an external act carried out by terrorists for any reason. They are therefore different both in the nature of the perpetrator and the reason for the act. The Centre for Chemical Process Safety has developed a guideline in its new initia- tive on sabotage risk in the process industry "[ that ]...demonstrates pro- cess and tools for managing the security 
vulnerability of sites that pro- duce and handle chemicals, petroleum products, pharmaceuticals, and related materials..."[35] . This study therefore introduces a third viola- tion subcategory named "acts of sabotage". However, this is related to the violation issue only insomuch as the act was internal and intended to trigger a domino effect within the process plant in response to an identified challenging organisational factor. This was also considered in HFACS-RR [17] .

\subsection{Preconditions for Unsafe Acts (Level 2)}

The preconditions for unsafe acts are linked to the categories of the Hawkins SHEL model where interaction between software, hardware, environment and liveware are considered factors that may create conditions for unsafe acts [36]. These interactions are represented in Figure 1.

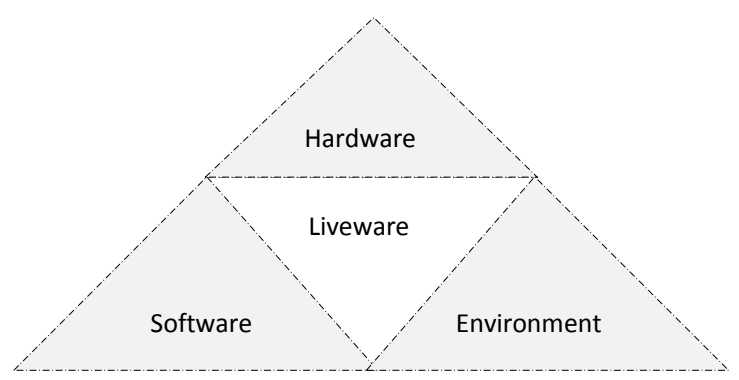

Figure 1: the SHEL Interactions

\subsubsection{Contractor Environment}

With respect to the original HFACS, the environmental factors were related only to physical and technological factors, some of which could be addressed within the context of a single company. The extensive use of contractor services and partnerships however, with their associated physical and technological environmental factors, has created a critical industry-wide problem. As a result, on average contract workers have consistently recorded a higher rate of fatal accidents (FAR) than company workers over the same period [37]. Moreover, the task errors associated with contractor accidents are to a greater extent due to physical and technological factors. The oil and gas industry operates with inputs from both short and long-term contractors which account for over $75 \%$ of hours worked in the industry worldwide [38]. Failures from contractors have been known to contribute to the majority of cases involving accidents in the industry [7,37, and 38]. This is because contractors are not permanent employees of any organisation and therefore may face challenges in adapting to a new working environment. Contractors may also have difficulties in adapting and merging their work patterns and safety cultures to that expected of them by the host organisation. These limitations may create the conditions for unsafe acts that may lead to accidents. Therefore, we considered it necessary for the oil and gas industry to properly address this challenge.

\subsubsection{Individual and Team Capacity}


The HFACS-OGI's category of individual and team capacity represents the physical, psychological and mental capacities of employees. With respect to the original HFACS, this category covers the operators' conditions in addition to the training and certification needs of the team. The oil and gas industry however requires individuals and teams with both technical and interpersonal skills to ensure that teams function effectively for safe operations [7].

\subsection{Organisational Influences (Level 4)}

\subsubsection{Management of Change}

Organisational influences, as constituted in the original HFACS, deal with "...decision[s] of upper management around three issues: 1) re- sources management, 2) organisational climate and 3) operational process..." [10]. However, with respect to the process industry and its safety management standards, the management of change refers to modifications (other than "replacement in kind ") to chemical processes, technology, equipment, procedures and changes to a facility that affect a covered process [39]. Significantly, many of the catastrophic events that have occurred on oil and gas facilities are attributable to the management of change [6]. There have also been numerous deficiencies in off shore process systems arising from the failure to effectively plan, communicate and coordinate process changes. When changes are not communicated properly and managed effectively, it could result in the conditions for accidents to occur [7, 40-44]. We have therefore added "management of change" as a subset of "organisational influences" to address the management of change as it relates to:

1. Process hardware / software modifications

2. Temporary process changes

3. Operating procedures changes

4. Process organisational changes

\subsubsection{Process Safety Culture}

Although there are similarities and some overlapping in the approaches to managing occupational safety and process safety, there are also significant differences due to their respective focus areas. Traditional occupational safety focuses on employees' health and safety in the workplace, for example slip, trip and fall, being hit by an object, getting caught in machinery, etc. Process safety however focuses on chemical releases, fires and explosions inherent in the process industry that can lead to catastrophic accidents. It has been noted that companies that do not have a distinctive process safety management programme tend to pay less attention to the process safety aspect of risk management, hence increasing the likelihood of catastrophic accidents. Following a number of industrial disasters including 'the 1984 Bhopal, India, incident resulting in more than 2000 deaths; the October 1989 Phillips Petroleum Company, Pasadena, TX, incident resulting in 23 deaths and 132 injuries; the July 1990 BASF, Cincinnati, OH, incident resulting in 2 deaths, and the May 1991 IMC, Sterlington, LA, incident resulting in 8 deaths and 128 injuries "; there 
has been an increased focus on the organisational process safety cultures associated with major accident hazards [29] . The Process Safety Leadership Group (PSLG) in their final report on the Buncefield incident advocated that the organisation should "develop a distinct programme for the promotion of process safety to support the maintenance of a positive process safety culture."[45, 46]. In July 1990, The Occupational Safety and Health Administration (OSHA) published Process Safety Management of Highly Hazardous Chemicals (July 1990), a proposed standard in the Federal Register (55 FR29150). The standard emphasised the requirement of a distinct hazard management associated with highly dangerous chemicals [39]. The UK Health and Safety Executive also developed distinct process safety indicators: a step-by-step guide for chemical and major hazard industries known as HSG254 [47]. The Control of Major Accident Hazards Regulations 1999 (COMAH) is a distinct set of regulations designed to ensure adequate emergency planning is in place for major accidents in the process industry [48] . The Competent Authority Strategic Management Group noted that a "board- level visibility and promotion of process safety leadership is essential to set a positive safety culture throughout an organisation [45]". There- fore, "process safety culture" has been introduced, a category distinct from organisational climate and designed to

\subsection{Regulatory \& Statutory Influences (Level 5)}

The contribution of factors in major accidents that go beyond the organisational level [49] was identified in the Deepwater Horizon (DWH) blowout of 2010 [50]. The accident killed 11 and released an estimated 4.1-4.6 million barrels (650,000 m 3) of oil into the Gulf of Mexico (Prouty et al., 2016). The DWH Study Group found that while this particular disaster involved organisational failures, it also transcended them: "this disaster involves an international industry and its governance. "This is similar to the level covering the industry governance or public governmental agencies [15, 20, and 51]. Regulatory and statutory influences or "industry-governance-management" are mainly concentrated on deficiencies with respect to national and international standards.

The first category in this level, which identifies deficiencies in cur- rent industry standards and approved codes of conducts, is named "international industry standards "while the second category is named the "national regulatory framework". The lack of industry-governance- management (national and international) in the oil and gas industry facilitates a progressive reduction in preventative barriers enabling in- appropriate cost cutting [50]. This environment can create preconditions for unsafe acts, similar to those in the Deepwater Horizon (DWH) blowout of 2010 [50].

\section{Accident analysis using the new framework}

The evaluation study to assess the suitability and to investigate key relationships between the categories of HFACS-OGI was conducted using major accidents that have occurred in the USA refineries. The International Association of Oil and Gas Procedures (OGP) defines major accidents as follows [52]:

i. $\quad$ multiple fatalities 
ii. ii. for offshore facility: total loss of the unit including constructive total loss from an insurance point of view, however, the unit may be repaired and put into operation again or severe damage to one or more modules of the unit; large /medium damage to loading bearing structure; major damage to major essential equipment.

iii. For onshore facility: approximately USD 100 M property damage or 1000 barrel of oil spilt [52]. In order to evaluate the HFACS-OGI framework, 11 refinery accident reports between 1998 and 2012 with at least one fatality or had extensive damage to the facility were retrieved from the CSB accident database. Refinery incidents that occurred due to natural causes (e.g. flooding, hurricane) were excluded.

In order to evaluate the HFACS-OGI framework, 11 refinery acci- dent reports between 1998 and 2012 with at least one fatality or had extensive damage to the facility were retrieved from the CSB accident database. Refinery incidents that occurred due to natural causes (e.g. flooding, hurricane) were excluded.

\subsection{Coding Process and Analysis}

Publically available U.S. refinery accident reports were coded based on the original 19 categories of HFACS and the 26 proposed categories of HFACS-OGI, as shown in Fig. 2. The coding identified the causal factors in each HFACS and HFACS-OGI category that contributed to these accidents. Each report was carefully read before the coding process for HFACS and HFACS-OGI. Each given category was coded 1 to indicate its presence or 0 to indicate its absence, as illustrated in Table 2. Although an accident may be caused by a combination of several factors, each particular unsafe act identified from the accident report was coded distinctly, considering all the subcategories of HFACS and HFACS-OGI. The coded data was then cross-tabulated for statistical analysis and any categories that were not present in any of the accidents were excluded. The SPSS version 22 for Windows was used to calculate the Chi-square test of association and Fisher's exact test in order to determine the statistical association between the upper-level categories and the adjacent lower level categories [14, 40, and 41]. Further analysis was conducted using Spearman's correlation [42] to measure the strength of the relationships between the different categories that showed significant relationships in the Chi-square and Fisher's exact test

Table 2

Illustration of the sequence of HFACS categories/subcategories identified from the accident/incident reports.

\begin{tabular}{cccccc}
\hline Year & Accident ID & \multicolumn{2}{c}{ Organisational influences } & $\begin{array}{c}\text { Level } 1 \\
\text { Tosource }\end{array}$ \\
\cline { 3 - 6 } & & management & Organisational climate & $\begin{array}{c}\text { Organisational } \\
\text { process }\end{array}$ & \\
\hline 2001 & $2001 \mathrm{~A}$ & 0 & 1 & 1 & 2 \\
2001 & $2001 \mathrm{~B}$ & 1 & 0 & 0 & 1 \\
2000 & $2000 \mathrm{~A}$ & 0 & 0 & 1 & 1 \\
2000 & $2000 \mathrm{~B}$ & 0 & 0 & 0 & 0 \\
2000 & 2000C & 0 & 0 & 0 & 0
\end{tabular}




\section{Results and Discussion}

\subsection{Assessment of external Contribution to Accident Causation}

The review of 11 refinery accidents using HFACS and HFACS-OGI is presented in Tables 3 and 4, showing the frequency of each of the identified contributory factors.

In identifying and describing the different causal factors in the 11 accidents reviewed (Tables 3 and 4), 54 categories of occurrences were identified with the HFACS, but a total of 80 were identified with HFACS- OGI. All industry specific categories which were difficult to identify with the HFACS were successfully identified using the HFACS-OGI.

The organisational process (level 4) was identified as a contributing factor in $90 \%$ of the accidents with a frequency of 10 each for both HFACS and HFACS-OGI. Process safety culture (HFACS-OGI level 4) was identified as a contributing factor in $63 \%$ of the accidents with a frequency of 7 , while organisational climate, resource management (HFACS \& HFACS-OGI level 4) and crew resource management (HFACS \& HFACS-OGI level 2) were identified in $54 \%$ of accidents as contributing factors with a frequency of 6 . Insufficient leadership support for a positive process safety culture was identified as a general factor in the process safety culture category. The lack of policies and procedures were common factors in the category of organisational process while failure to provide sufficient resources for the procurement of equipment and bud- get cuts were common failures in the resource management category. The common factors identified in crew resource management include in- sufficient workforce, poor team communication, poor job planning and a lack of teamwork. The contributing factors identified in $45 \%$ of the accidents include industry standards (HFACS-OGI level 5), management of change (HFACS- OGI level 4), contractor environment (HFACS-OGI level 2) and decision errors (HFACS \& HFACS-OGI level 1) with a frequency occurrence of 5 each. The common factors identified in the management of change category were the failure to conduct sufficient management of change re- views for process hardware / software modifications and the lack of updated operating procedures following modification. This demonstrates the importance of adding this category to HFACS-OGI. The factors identified in the contractor environment included the failure of the contractor to follow client workplace procedures and poor quality of services. The inability to make safe decisions to produce desired results was common in decision errors.

The contributing factors identified in $36 \%$ of the accidents include the national regulatory framework (HFACS-OGI level 5), inadequate supervision (HFACS \& HFACS-OGI level 3) and supervisory violations (HFACS \& HFACS-OGI level 3) with a frequency occurrence of 4 each.

The common factors identified in the HFACS-OGI national regulatory framework category were failures in administrative duties such as inspections and the enforcement of regulations, in addition to inadequate regulatory standards. 
A lack of sufficient supervision and support was common in all accidents that had inadequate supervision as one of their contributing factors. The failure to follow the rules and procedures by supervisors was the most common failure in the supervisory violation category.

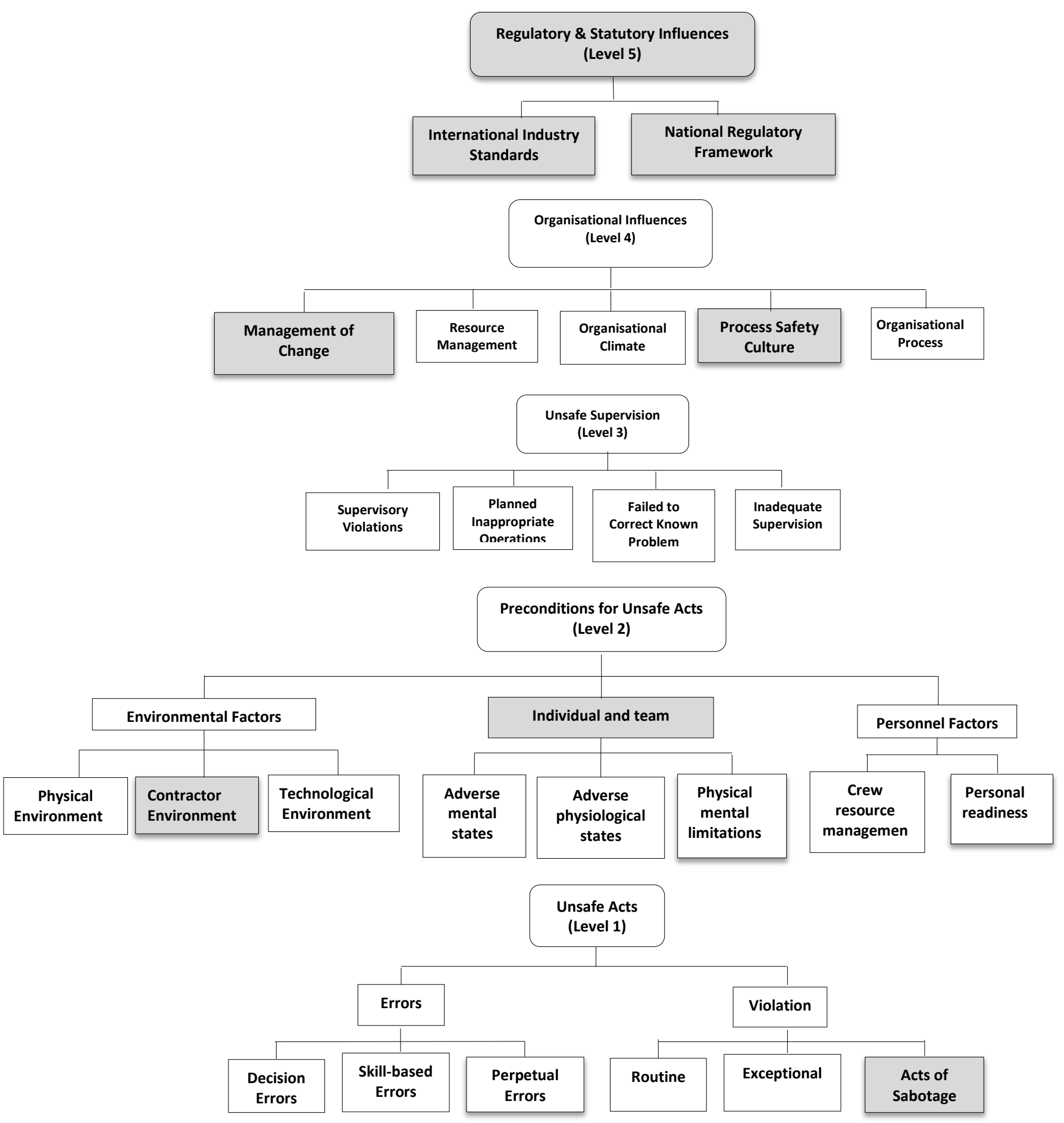

Figure 2: Proposed framework for HFACS-OGI 
Table 3:

Breakdown of accident/incident contributing to HFACS categories

\begin{tabular}{|c|c|c|c|}
\hline HFACS Level & Subcategory & $\begin{array}{l}\text { Number of cases } \\
\text { identified per contributing } \\
\text { subcategory }\end{array}$ & $\begin{array}{c}* \text { Percentage } \\
\%\end{array}$ \\
\hline Level 4 & Organisational process & 10 & 90 \\
\hline Organisational & Organisational climate & 6 & 54 \\
\hline influences & Resource management & 6 & 54 \\
\hline Level 3 & Inadequate supervision & 4 & 36 \\
\hline Unsafe & Planned inappropriate operations & 2 & 18 \\
\hline \multirow[t]{2}{*}{ supervision } & Failed to correct a known problem & 1 & 9 \\
\hline & Supervisory Violations & 4 & 36 \\
\hline Level 2 & Physical environment & 1 & 9 \\
\hline Preconditions & Technological environment & 2 & 18 \\
\hline \multirow[t]{5}{*}{ for unsafe acts } & Adverse mental states & 1 & 9 \\
\hline & Adverse physiological states & 0 & - \\
\hline & Physical/ mental limitations & 0 & - \\
\hline & Crew resource management & 6 & 54 \\
\hline & Personal readiness & 1 & 9 \\
\hline Level 1 & Decision errors & 5 & 45 \\
\hline \multirow[t]{4}{*}{ Unsafe acts } & Skill-based errors & 1 & 9 \\
\hline & Perceptual errors & 1 & 9 \\
\hline & Routine violations & 2 & 18 \\
\hline & Exceptional violations & 1 & 9 \\
\hline
\end{tabular}

*The column labelled percentage reflects the overall percentage among all cases. Note that the percentage will not equal $100 \%$, because in many cases far more than one causal factor was associated with the accident

Three contributory factors were identified in $18 \%$ of the accidents including planned inappropriate operations (HFACS \& HFACS-OGI level 3), the technological environment (HFACS \& HFACS-OGI level 2) and routine violations (HFACS and HFACS-OGI level 1) with a frequency occurrence of 2 each. The failure to plan work in a safe manner and the issuing of inadequate work permits were the issues found in planned inappropriate operations. The failure of alarms and critical safety dis- play systems were identified in the technology environment category, while failure to follow work procedures as general practice in carrying out certain tasks was identified in the routine violations category.

The contributing factors with a $9 \%$ presence in the accidents were as follows: the failure to correct known problem (HFACS and HFACS-OGI level 3), the physical environment and adverse mental states (HFACS and HFACS-OGI level 2), skill-based errors, perceptual errors and exceptional violation (HFACS and 
HFACS-OGI level 1) with a frequency occurrence of 1 each. The failure of duty supervisors to control known existing hazards prior to maintenance was identified under the failure to correct a known problem, the main failure in the physical environment involved operators working at a height without safety precautions along with ignition sources. The inability to follow procedures due to the pressure of time was found in the exceptional violations category.

The three categories not included in the results are adverse physiological states, physical/mental limitations (HFACS and HFACS-OGI level 2) and acts of sabotage (HFACS-OGI level 1), because they were not identified as contributing factors in the accidents under analysis. The results show the presence of industry standards and national regulatory framework failures in some of the accidents reviewed. This may not have been possible with the application of the original HFACS because it does not provide a category for industry standards and the national regulatory framework, or a level to consider other factors.

International standards and national regulatory framework categories were identified as contributing factors in some accidents and this reaffirms similar findings in recent studies [14, 15, 19, and 53]. This indicates that sufficient regulatory responsibility is particularly important in the oil and gas industry. Not all accidents however have industry standards and national regulatory framework failures as contributing factors, as discovered by other researchers $[17,20]$.

The key failures identified in level 4 of HFACS-OGI were a lack of financial resources and inadequate procedures including the lack of procedures for certain aspects of the operations. These identified factors are consistent with findings from other researchers, as this indicates that failures at this level contribute to accidents $[18,53]$.

Overall, these findings validate the application of HFACS-OGI as an effective human factor analysis tool in accident investigation for the oil and gas industry.

The results indicate that $50 \%$ of the contributing factors identified in the 11 accidents reviewed are latent failures in level 2 and level 4, this shows that it is possible for the failures created at higher levels to remain in the system for a considerable time without being noticed, thereby creating conditions for accidents to occur during operations $[54,55]$.

\subsubsection{Evaluation of the relationships between HFACS and HFACS-OGI levels}

This section provides the results and discussion regarding the evaluation of the relationships between upper-level categories and adjacent downward level categories in the HFACS and HFACS-OGI frameworks. A summary of results showing only the significant associations from the Chi-square and Fisher's exact tests are shown in Tables 5 and 6. The summary results for Spearman's correlation, conducted only for HFACS OGI, are shown in Table 7 including details of the strengths of association. Although the HFACS analysis identified some significant associations in the 11 refinery accidents, the number and strength of significant associations identified using the HFACS-OGI validate the efficiency of its application in the oil and gas industry.

The significant association paths based on the Chi-square test and Fisher's exact test between the upper the level and adjacent downward level categories in the HFACS-OGI framework are illustrated in Fig. 3 . 
Fig. 3 shows a representation of all the findings of the Chi-square test of association, Fisher's exact test and Spearman's correlation test from level 5 to level 1. For example, there was a significant association between the national regulatory framework (level 5) and organisational climate (level 4) $(\mathrm{r}=0.022, \mathrm{p}<0.05)$. Fisher's exact test was statistically significant $(r=0.015, \mathrm{p}<0.05)$. Spearman's correlation test between the national regulatory framework (level 5) and the organisational climate (level 4) showed a very strong positive association $(r=0.690, p<0.01)$. Fig. 3 shows that some categories were statistically significant in the Chisquare test of association but not all categories were significant in Fisher's exact test and Spearman's correlation. Spearman's correlation (Table 7) however also provided a type of association between the various categories.

4.1.2. The Chi-square test, Fisher's exact test and Spearman's correlation analysis The Chi-square test, Fisher's exact test and Spearman's correlation analysis of the categories in the different HFACS-OGI and HFACS levels have demonstrated varying statistical associations between the different levels, some of which are common to safety critical domains as identified by previous HFACS analysis.

The level 5 failures involving the national regulatory framework demonstrate the potential of these external factors to create the conditions where organisations are unable to put in place effective structures based on best practices and regulations. These industry standards and national regulations could have provided the reference guidelines for communication, delegation of authority, human resources policies, positive norms, organisational customs, values and beliefs to enable them to operate safely, but deficiencies of industry codes and national regulations have been identified as key factors that may both prevent and also contribute to accidents [17, 19, and 56]. According to Olsen and Shamrock [22], external factors such as regulations may influence certain aspects of the organisational process. This indicates that regulations may affect categories in level 4 , as seen in this study. The deficiencies in national regulatory frameworks may create a conducive environment for accidents at the top level of the organisation because top management may lack direction on best practices [15]. However, national regulatory frameworks may also create regulations and standards to enable organisations to reduce and prevent accidents [57]. The management of change failure in level 4 may lead to inadequate supervision and potentially serious consequences.

The failures of inadequate supervision, the failure to correct known problems and planned inappropriate operations on three level 2 and level 3 categories demonstrates the importance of adequate supervision, especially in the management of individual and team capacity in the execution of tasks. The path of significant association reveals this connection. It may also affect the way individuals and team members handle process changes in the workplace, together with their ability to make decisions based on the risk perception profile of both the supervisor and the entire team. This further validates the importance of effective supervisory arrangements in an organisation as a vital factor in the prevention of accidents because inadequate supervision has been identified as a causal factor in accidents [58, 59]. 
Table 4:

Breakdown of accident/incident contributing to HFACS-OGI categories

\begin{tabular}{|c|c|c|c|}
\hline HFACS -OGI & Subcategory & $\begin{array}{c}\text { Number of cases } \\
\text { identified per contributing } \\
\text { factor } \\
\end{array}$ & $\begin{array}{c}* \text { Percentage } \\
\%\end{array}$ \\
\hline Level 5 & & & \\
\hline Regulatory \& & Industry standards & 5 & 45 \\
\hline $\begin{array}{c}\text { Statutory } \\
\text { Influences } \\
\end{array}$ & National regulatory framework & 4 & 36 \\
\hline \multirow{5}{*}{$\begin{array}{c}\text { Level } 4 \\
\text { Organisational } \\
\text { Influences }\end{array}$} & Organisational climate & 6 & 54 \\
\hline & Process safety culture & 7 & 63 \\
\hline & Organisational process & 10 & 90 \\
\hline & Management of Change & 5 & 45 \\
\hline & Resource management & 6 & 54 \\
\hline \multirow{4}{*}{$\begin{array}{c}\text { Level } 3 \\
\text { Unsafe } \\
\text { Supervision }\end{array}$} & Inadequate supervision & 4 & 36 \\
\hline & Planned inappropriate operations & 2 & 18 \\
\hline & Failed to correct a known problem & 1 & 9 \\
\hline & Supervisory Violations & 4 & 36 \\
\hline \multirow{8}{*}{$\begin{array}{l}\text { Level } 2 \\
\text { Preconditions } \\
\text { for Unsafe } \\
\text { Acts }\end{array}$} & Physical environment & 1 & 9 \\
\hline & Technological environment & 2 & 18 \\
\hline & Contractor environment & 5 & 45 \\
\hline & Adverse mental states & 1 & 9 \\
\hline & Adverse physiological states & 0 & - \\
\hline & Physical / mental limitations & 0 & - \\
\hline & Crew resource management & 6 & 54 \\
\hline & Personal readiness & 1 & 9 \\
\hline \multirow{6}{*}{$\begin{array}{c}\text { Level } 1 \\
\text { Unsafe Acts }\end{array}$} & Decision errors & 5 & 45 \\
\hline & Skill-based errors & 1 & 9 \\
\hline & Perceptual errors & 1 & 9 \\
\hline & Routine violations & 2 & 18 \\
\hline & Exceptional violations & 1 & 9 \\
\hline & Acts of sabotage & 0 & - \\
\hline
\end{tabular}

Table 5:

* Comparison of Chi-Square and Fisher's Exact Test Results between levels of HFACS framework

\begin{tabular}{|c|c|c|c|c|c|}
\hline \multirow{2}{*}{\multicolumn{2}{|c|}{$\begin{array}{l}\text { A significant association between the upper } \\
\text { level and adjacent downward level categories } \\
\text { in the HFACS framework. } \\
P \text {-values less than } 0.05 \text { indicate a significant } \\
\text { relationship between categories. }\end{array}$}} & \multicolumn{2}{|c|}{ Chi-square } & \multicolumn{2}{|c|}{ Fisher's exact test } \\
\hline & & P-value & $\begin{array}{l}\text { Significance } \\
\mathrm{P}<0.05\end{array}$ & P-value & $\begin{array}{l}\text { Significance } \\
\mathrm{P}<0.05\end{array}$ \\
\hline Inadequate supervision & $\begin{array}{l}\text { Technological } \\
\text { environment }\end{array}$ & 0.039 & Yes & 0.109 & No \\
\hline Inadequate supervision & $\begin{array}{l}\text { Crew resource } \\
\text { management }\end{array}$ & 0.022 & Yes & 0.061 & No \\
\hline $\begin{array}{l}\text { Planned inappropriate } \\
\text { operations }\end{array}$ & $\begin{array}{l}\text { Physical } \\
\text { environment }\end{array}$ & 0.026 & Yes & 0.182 & No \\
\hline $\begin{array}{l}\text { Failed to correct known } \\
\text { problem }\end{array}$ & $\begin{array}{l}\text { Physical } \\
\text { environment }\end{array}$ & 0.001 & Yes & 0.091 & No \\
\hline Physical Environment & Skilled Based & 0.001 & Yes & 0.091 & No \\
\hline
\end{tabular}




\begin{tabular}{llcccc} 
Technological Environment & $\begin{array}{l}\text { Errors } \\
\text { Perceptual } \\
\text { Errors }\end{array}$ & 0.026 & Yes & 0.182 & No \\
Adverse Mental States & $\begin{array}{l}\text { Perceptual } \\
\text { Errors } \\
\text { Routine } \\
\text { Adverse Mental States }\end{array}$ & 0.001 & Yes & 0.091 & No \\
& $\begin{array}{l}\text { Violations } \\
\text { Perceptual } \\
\text { Errors } \\
\text { Routine } \\
\text { Violations }\end{array}$ & 0.001 & Yes & 0.091 & No \\
Personal Readiness & 0.026 & Yes & 0.182 & No \\
& & & & & \\
\hline
\end{tabular}

Table 6:

* Comparison of Chi-Square and Fisher's Exact Test Results between levels of HFACS-OGI framework

\begin{tabular}{|c|c|c|c|c|c|}
\hline \multirow{2}{*}{\multicolumn{2}{|c|}{$\begin{array}{l}\text { A significant association between the upper level and } \\
\text { adjacent downward level categories in the HFACS- } \\
\text { OGI framework. } \\
P \text {-values less than } 0.05 \text { indicate a significant } \\
\text { relationship between categories. }\end{array}$}} & \multicolumn{2}{|c|}{ Chi-square } & \multicolumn{2}{|c|}{ Fisher's exact test } \\
\hline & & $\begin{array}{c}\mathrm{P}- \\
\text { value }\end{array}$ & $\begin{array}{c}\text { Sig } \\
\mathbf{P}<0.05\end{array}$ & $\begin{array}{c}\mathrm{P}- \\
\text { value }\end{array}$ & $\begin{array}{c}\text { Sig } \\
\mathrm{P}<0.05\end{array}$ \\
\hline National regulatory framework & $\begin{array}{l}\text { Organisational } \\
\text { climate }\end{array}$ & 0.022 & Yes & 0.061 & No \\
\hline Management of Change & $\begin{array}{l}\text { Inadequate } \\
\text { Supervision }\end{array}$ & 0.006 & Yes & 0.015 & Yes \\
\hline Inadequate supervision & $\begin{array}{l}\text { Technological } \\
\text { environment }\end{array}$ & 0.039 & Yes & 0.109 & No \\
\hline Inadequate supervision & $\begin{array}{l}\text { Crew Resource } \\
\text { Management }\end{array}$ & 0.022 & Yes & 0.061 & No \\
\hline $\begin{array}{l}\text { Planned inappropriate } \\
\text { operations }\end{array}$ & $\begin{array}{l}\text { Physical } \\
\text { Environment }\end{array}$ & 0.026 & Yes & 0.182 & No \\
\hline $\begin{array}{l}\text { Failed to Correct Known } \\
\text { Problem }\end{array}$ & $\begin{array}{l}\text { Physical } \\
\text { Environment }\end{array}$ & 0.001 & Yes & 0.091 & No \\
\hline Physical Environment & Skill-Based Errors & 0.001 & Yes & 0.091 & No \\
\hline Technological Environment & Perceptual Errors & 0.026 & Yes & 0.182 & No \\
\hline Adverse Mental States & Perceptual Errors & 0.001 & Yes & 0.091 & No \\
\hline Adverse Mental States & Routine violation & 0.026 & Yes & 0.182 & No \\
\hline Personal Readiness & Perceptual Errors & 0.001 & Yes & 0.091 & No \\
\hline Personal Readiness & Routine Violations & 0.026 & Yes & 0.182 & No \\
\hline
\end{tabular}

Table 7:

*Spearman's Correlation Summary Results of HFACS-OGI framework

\begin{tabular}{|c|c|c|}
\hline \multirow{2}{*}{$\begin{array}{l}\text { Strength of association between upper level and adjacent } \\
\text { downward level categories in the HFACS-OGI framework. }\end{array}$} & \multicolumn{2}{|c|}{ Spearman's Correlation } \\
\hline & Significance & $\begin{array}{l}\text { Level of } \\
\text { Significance }\end{array}$ \\
\hline
\end{tabular}




\begin{tabular}{|c|c|c|c|c|}
\hline $\begin{array}{l}\text { National Regulatory } \\
\text { Framework }\end{array}$ & Organizational Climate & 0.690 & 0.019 & 0.05 \\
\hline Management of Change & Inadequate Supervision & 0.828 & 0.002 & 0.01 \\
\hline Inadequate supervision & Technological environment & 0.624 & 0.040 & 0.05 \\
\hline Inadequate supervision & $\begin{array}{l}\text { Crew Resource } \\
\text { Management }\end{array}$ & 0.690 & 0.019 & 0.05 \\
\hline $\begin{array}{l}\text { Planned inappropriate } \\
\text { operations }\end{array}$ & Physical Environment & 0.671 & 0.024 & 0.05 \\
\hline $\begin{array}{l}\text { Failed to Correct Known } \\
\text { Problem }\end{array}$ & Physical Environment & 1.0000 & . & 0.01 \\
\hline Physical Environment & Skill-Based Errors & 1.0000 & . & 0.01 \\
\hline Technological Environment & Perceptual Errors & 0.671 & 0.024 & 0.05 \\
\hline Adverse Mental States & Perceptual Errors & 1.0000 & . & 0.01 \\
\hline Adverse Mental States & Routine Violations & 0.671 & 0.024 & 0.05 \\
\hline Personal Readiness & Perceptual Errors & 1.0000 & $\cdot$ & 0.01 \\
\hline Personal Readiness & Routine Violations & 0.671 & 0.024 & 0.05 \\
\hline
\end{tabular}

*Only Significant P-values are shown.

The path of association shows it is possible for advanced mental stress and inadequate personal preparation to create the conditions for routine violations. It is possible for both the technological environment and adverse mental states to create the conditions for significant errors.

This current study was based on a very limited number of publicly available refinery accident/incident reports between 1998 and 2012 suffering at least one fatality or extensive damage to the facility. These were retrieved from the CSB accident database. A more comprehensive analysis using the HFACS-OGI would have been possible had a larger and more varied report been used. The use of only publicly available accident/incident reports from the CSB accident database also limits the conclusions that can be drawn from this analysis; as the sample size may not adequately represent the full range of possible accident causal factors in the oil and gas industry. However, although this is a representative sample, the result clearly showed that HFAC-OGI was useful in identifying unsafe acts, preconditions for unsafe acts, unsafe supervision, organisational influences and regulatory and statutory influences in the oil and gas industry. To reiterate, although the sample size is recognised as a limitation, this limitation does not undermine the re- search outcomes and the potential application of this method. 


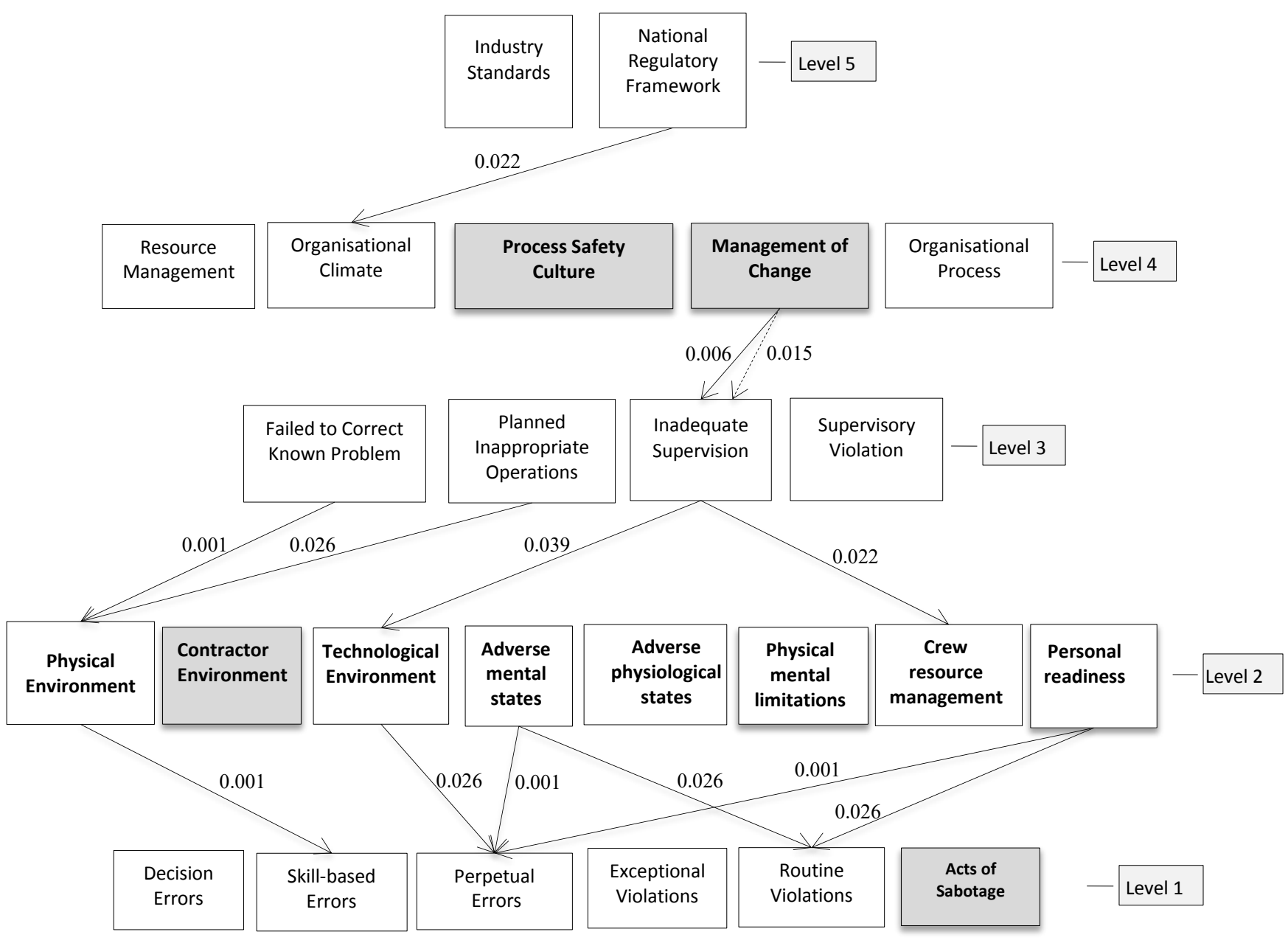

Figure 3: Paths of associations between HFACS-OGI levels

(Chi-square Test $\longrightarrow$ Fisher's Exact Test $\quad \cdots \cdots \cdots$

\section{Conclusions}

This study proposed the HFACS-OGI framework to address the short- comings in the original HFACS framework for the oil and gas industry. HFACS-OGI was successfully applied to the oil and gas industry context with a special focus on refinery accidents in the USA. The HFACS-OGI analysis identified significant themes in the 11 re- finery accidents analysed to validate its efficiency of application in the oil and gas industry. Some of the significant themes include the national regulatory framework, industry standards, management of change, the contractor environment and the process safety culture. International standards and the national regulatory framework were identified as contributing to accident causation in the oil and gas industry. These identified themes were not in the original HFACS but were identified using the HFACS-OGI showing the greater efficiency and robustness of the HFACS-OGI. The statistical analysis of associations between the different levels identified important relationships such as level 5 categories having some association with the organisational climate and supervision having influence on some level 2 categories such as the technological environment and crew resource management. These findings 
demonstrate the efficiency and applicability of HFACS-OGI as an important HSE tool for the analysis of accidents in the oil and gas industry.

\section{References}

[1] Kariuki SG, Löwe K. Integrating human factors into process hazard analysis. Reliab Eng Syst Saf 2007;92:1764-73. doi: 10.1016/j.ress.2007.01.002 .

[2] Manca D, Brambilla S. Dynamic simulation of the BP Texas City refinery accident. J Loss Prev Process Ind 2012;25:950-7. doi: 10.1016/j.jlp.2012.05.008 .

[3] Mishra KB. CFD model for large hazardous dense cloud spread predictions, with particular reference to Bhopal disaster. Atoms Environ 2015; 117:74-91. doi: 10.1016/ j.atmosenv.2015.06.038.

[4] Venart JES. Flixborough: the explosion and its aftermath. Process Saf Environ Port 2004; 82:105-27. doi: 10.1205/095758204322972753.

[5] The U.S. Chemical Safety Board. Giant industries refinery explosions and fire - investigations | the U.S. Chemical Safety Board 2005. http://www.csb.gov/ giant- industries- refinery- explosions- and- fire/ (accessed April 11, 2016).

[6] Singh B, Jukes P, Poblete B, Wittkower B. 20 years on lessons learned from Piper Alpha. The evolution of concurrent and inherently safe design. J Loss Prev Process Ind 2010; 23:936-53. doi: 10.1016/j.jlp.2010.07.011.

[7] SPE. The human factor: process safety and culture, 2014. doi: NULL.

[8] Shappell S, Detwiler C, Holcomb K, Hackworth C, Boquet A, Wiegmann DA. Human error and commercial aviation accidents: an analysis using the human factors analysis and classification system. Hum Factors J Hum Factors Ergon Soc 2007; 49:227-42. doi: 10.1518/001872007X312469.

[9] Shappell PSA, Wiegmann PDA. A human error approach to aviation accident analysis: the human factors analysis and classification system. Ashgate Publishing, Ltd.; 2012.

[10] Wiegmann D.A., Shappell. A human error analysis of commercial aviation accidents using the Human Factors Analysis and Classification System (HFACS). n.d.

[11] Wiegmann DA, Shappell SA. A human error approach to aviation accident analysis. ResearchGate 2003.

[12] Diller T, Helmrich G, Dunning S, Cox S, Buchanan A, Shappell S. The Human Factors Analysis Classification System (HFACS) applied to health care. Am J Med Qual OffJ Am Coll Med Qual 2014; 29:181-90. doi: 10.1177/1062860613491623.

[13] Baysari MT, McIntosh AS, Wilson JR. Understanding the human factors contribution to railway accidents and incidents in Australia. Accid Anal Prev 2008; 40:1750-7. doi: 10.1016/j.aap.2008.06.013.

[14] Chauvin C, Lardjane S, Morel G, Clostermann J-P, Langard B. Human and organisational factors in maritime accidents: analysis of collisions at sea using the HFACS. Accid Anal Prev 2013; 59:26-37. doi: 10.1016/j.aap.2013.05.006. 
[15] Chen S-T, Wall A, Davies P, Yang Z, Wang J, Chou Y-H. A Human and Organisational Factors (HOFs) analysis method for marine casualties using HFACS-Maritime Accidents (HFACS-MA). Saf Sci 2013;60:105-14. doi: 10.1016/j.ssci.2013.06.009 .

[16] Milligan FJ. Establishing a culture for patient safety - the role of education. Nurse Educ Today 2007;27:95-102. doi: 10.1016/j.nedt.2006.03.003.

[17] Reinach S, Viale A. Application of a human error framework to conduct train accident/incident investigations. Accid Anal Prev 2006;38:396-406. doi: 10.1016/j.aap. 2005.10.013.

[18] Soner O, Asan U, Celik M. Use of HFACS-FCM in fire prevention modelling on board ships. Saf Sci 2015; 77:25-41. doi: 10.1016/j.ssci.2015.03.007.

[19] Schröder-Hinrichs JU, Baldauf M, Ghirxi KT. Accident investigation reporting deficiencies related to organizational factors in machinery space fires and explosions. Accid Anal Prev 2011;43:1187-96. doi: 10.1016/j.aap.2010.12.033.

[20] Patterson JM, Shappell SA. Operator error and system deficiencies: analysis of 508 mining incidents and accidents from Queensland, Australia using HFACS. Accid Anal Prev 2010;42:1379-85. doi: 10.1016/j.aap.2010.02.018.

[21] Hale A, Walker D, Walters N, Bolt H. Developing the understanding of underlying causes of construction fatal accidents. Saf Sci 2012; 50:2020-7. doi: 10.1016/j.ssci. 2012.01.018.

[22] Inglis M, Smithson MJ, Cheng K, Stanton DR, Godley ST. Evaluation of the human factors analysis and classification system as a predictive model. Aviation Research and Analysis Report AR-2008036. Australian: Australian Transport Safety Bureau; 2010.

[23] Olsen NS, Shorrock ST. Evaluation of the HFACS-ADF safety classification system: inter-coder consensus and intra-coder consistency. Accid Anal Prev 2010; 42:437-44. doi: 10.1016/j.aap.2009.09.005. [24] Rashid HSJ, Place CS, Braithwaite GR. Helicopter maintenance error analysis: be- yond the third order of the HFACS-ME. Int J Ind Ergon 2010; 40:636-47. doi: 10. 1016/j.ergon.2010.04.005.

[25] Theophilus SC, Shaibu JH. Assessing leadership and employee safety participation in managing health and safety: a case study of K-Refinery and Petrochemical Companies (K-RPC). In: Energy Sustain. V, vol. 206. Putrajaya, Malaysia: WIT Press; 2014. p. 69-79. doi: 10.2495/ESUS140061 .

[26] Pasman HJ, Knegtering B, Rogers WJ. A holistic approach to control process safety risks: Possible ways forward. Reliab Eng Syst Saf 2013; 117:21-9. doi: 10.1016/j.ress. 2013.03.010.

[27] Knegtering B, Pasman HJ. Safety of the process industries in the 21 st century: a changing need of process safety management for a changing industry. J Loss Prev Process Ind 2009;22:162-8. doi: 10.1016/j.jlp.2008.11.005 .

[28] Kidam K, Hurme M. Analysis of equipment failures as contributors to chemical pro- cess accidents. Process Saf Environ Prot 2013;91:61-78. doi: 10.1016/j.psep.2012. 02.001.

[29] O'Dea A, Flin R. Site managers and safety leadership in the offshore oil and gas industry. Saf Sci 2001;37:39-57. doi: 10.1016/S0925- 7535(00)00049- 7. 
[30] OGP. Glossary of HSE terms. International Association of Oil and Gas Producers; 1999.

[31] Bridges W, Tew R. Human factors elements missing from process safety management (PSM). In: 6th Glob. Congr. Process Saf. 44th Annu. Loss Prev. Symp. San Antonio Tex.; 2010. p. 22-4.

[32] Yang M, Khan F, Amyotte P. Operational risk assessment: a case of the Bhopal dis- aster. Process Saf Environ Prot 2015; 97:70-9. doi: 10.1016/j.psep.2015.06.001 .

[33] Kalelkar AS, Little AD. Investigation of large-magnitude incidents: Bhopal as a case study. AD Little London; 1988.

[34] Argenti F, Landucci G, Reniers G. Probabilistic vulnerability assessment of chemical clusters subjected to external acts of interference. Chem Eng Trans 2016;48:691-6. doi: 10.3303/CET1648116.

[35] American Institute of Chemical Engineers, editor. Guidelines for analysing and man- aging the security vulnerabilities of fixed chemical sites. New York: Center for Chemical Process Safety of the American Institute of Chemical Engineers; 2003.

[36] Molloy GJ, O’Boyle CA. The SHEL model: a useful tool for analyzing and teaching the contribution of Human Factors to medical error. Acad Med J Assoc Am Med Coll 2005; 80:152-5.

[37] Graham I. Working conditions of contract workers in the oil and gas industries. 2010.

[38] IOGP. Health \& safety incident reporting system users 'guide, 2012 data. International Association of Oil \& Gas Producers; 2013.

[39] U.S. Department of Labor. Process safety management 2000.

[40] Hayes J. Operator competence and capacity — lessons from the Montara blowout. Saf Sci 2012;50:56374. Doi: 10.1016/j.ssci.2011.10.009.

[41] U.S. CSB. Valero - Mckee refinery propane fire. U.S. Chemical Safety and Hazard Investigation Board; 2008.

[42] U.S. CSB. BP America refinery explosion. U.S. Chemical Safety and Hazard Investigation Board; 2007.

[43] U.S. CSB. Motiva enterprises sulphuric acid tank explosion. U.S. Chemical Safety and Hazard Investigation Board; 2002.

[44] U.S. CSB. Tosco Avon refinery petroleum naphtha fire. U.S. Chemical Safety and Hazard Investigation Board; 2001.

[45] PSLG. Great Britain, health and safety executive. Safety and environmental standards for fuel storage sites: final report. London: HSE Books; 2009.

[46] Frank WL. Process safety culture in the CCPS risk based process safety model. Process Saf Prog 2007; 26:203-8. doi: 10.1002/prs.10201.

[47] Great Britain, Health and Safety Executive. Developing process safety indicators: a step-by-step guide for chemical and major hazard industries. Sudbury: Health and Safety Executive; 2006.

[48] Emergency planning for major accidents: Control of Major Accident Hazards Regulations 1999 (COMAH) - HSG191 n.d. http://www.hse.gov.uk/pubns/books/hsg191. htm (accessed April 3, 2017). 
[49] Chen S-T, Wall A, Davies P, Yang Z, Wang J, Chou Y-H. A Human and Organisational Factors (HOFs) analysis method for marine casualties using HFACS-Maritime Accidents (HFACS-MA). Saf Sci 2013;60:105-14. Doi: 10.1016/j.ssci.2013.06.009. [50] U.S. CSB. Final report: Macondo investigations report, vol. 2. U.S. Chemical Safety and Hazard Investigation Board; 2014.

[51] Reinach S, Viale A. Application of a human error framework to conduct train accident/incident investigations. Accid Anal Prev 2006; 38:396-406. doi: 10.1016/j.aap. 2005.10.013.

[52] IOGP. Major accidents —risk assessment data directory. 2010.

[53] Mazaheri A, Montewka J, Nisula J, Kujala P. Usability of accident and incident re- ports for evidencebased risk modeling - $\mathrm{a}$ case study on ship grounding reports. Saf Sci 2015; 76:202-14. doi: 10.1016/j.ssci.2015.02.019.

[54] Li W-C, Harris D. Pilot error and its relationship with higher organizational levels: HFACS analysis of 523 accidents. Aviat Space Environ Med 2006;77:1056-61.

[55] Reason J. The contribution of latent human failures to the breakdown of complex systems. Philos Trans R Soc Lond B Biol Sci 1990; 327:475-84.

[56] Mendes PAS, Hall J, Matos S, Silvestre B. Reforming Brazil's offshore oil and gas safety regulatory framework: lessons from Norway, the United Kingdom and the United States. Energy Policy 2014; 74:443-53. doi: 10.1016/j.enpol.2014.08.014.

[57] Monforton C, Windsor R. An impact evaluation of a federal mine safety training regulation on injury rates among US stone, sand, and gravel mine workers: an interrupted time-series analysis. Am J Public Health 2010; 100:1334-40? doi: 10.2105/ AJPH.2009.178301.

[58] Brazier A, Gait A, Waite P. Great Britain, health and safety executive, Entec UK Limited. Different types of supervision and the impact on safety in the chemical and allied industries. Sudbury: HSE Books; 2004.

[59] LennéMG, Salmon PM, Liu CC, Trotter M. A systems approach to accident causation in mining: an application of the HFACS method. Accid Anal Prev 2012; 48:111-17. doi: 10.1016/j.aap.2011.05.026. 